\title{
Factors affecting patient flow planning in hospitals
}

\author{
Abdelrahman E. M. Ezzat ${ }^{1}$, Hesham S. Hamoud ${ }^{2}$ and Bader E. Fadlallah ${ }^{3}$ \\ ${ }^{I}$ Associated lecture, (MBBCh, MSc, MRCS, DOHNS \& MBA-hosp), ENT Department, Faculty of Medicine, Al-Azhar \\ University- Cairo-Egypt. \\ ${ }^{2}$ Professor, (MBBCh, MSc, MD \& MBA-Hosp) Rheumatology Department, Faculty of Medicine, Al-Azhar University- \\ Cairo-Egypt. \\ ${ }^{3}$ Professor, (MBBCh, MSc, MD \& MBA-Hosp) Anesthesiology Department, Faculty of Medicine, Al-Azhar University- \\ Cairo-Egypt.
}

\begin{abstract}
Patient flow management is considered a persistent and refractory problem in most countries surveyed. However, now, the ability to perform such analyses is severely limited by a lack of data. In most countries, there is no link between ambulatory and non-ambulatory patient data, which makes it difficult to carry out studies that find out common factors that affect these flows. Hence, by knowing the factors that have a negative influence on the efficiency of patient flow planning and the factors that have a positive influence, the efficiency of the hospital could be increased through overcoming the negative factors and improving the positive one.
\end{abstract}

Key words: Patient Flow, Health Care, Patient Satisfaction

\section{Introduction}

Flow is not about the what of clinical care decisions, but about the how, where, when and who of care provision. How services are accessed, when and where assessment and treatment is available, and who it is provided by, can have as significant an impact on the quality of care as the actual clinical care received ${ }^{(1)}$.

More and more hospitals are nowadays focused on making their internal processes as efficient as possible, so that time and money are optimally used ${ }^{(2,3)}$. Patient flow represents the ability of the healthcare system to serve patients quickly and efficiently as they move through stages of care. Blockage in the flow can increase waiting and through put time creating a negative effect on the quality of service delivery ${ }^{(4)}$. When patient flow is handled well, it is represented by short wait at registration, examination, diagnostic testing, surgery, placement in beds, and discharge ${ }^{(5)}$. Thus, improving patient flow is one way of improving healthcare services. Furthermore, they have to improve quality of the services provided to keep them competing within the industry, as is said by Cayirli and Veral ${ }^{(6)}$.

According to Haraden and Resar ${ }^{(7)}$, one of the ways to accomplish this is by optimizing the patient flow planning aspect by understanding this process better. Therefore, there will be looked at the different factors that influence patient flow planning and how to deal with these factors influencing the efficiency of patient flow planning.

\section{Literature and Discussion}

There are factors that influence the efficiency level of patient flow planning in a worsening factor and there are factors with an improving influence.

The factors that have a (negative, bad or worsen) influence, meaning the higher the existence of this factor, the lower the efficiency level of patient flow planning will become. Factors that influence theefficiency of patient flow planning in bad way are: complexity, limited resources, uncertainty, joiner stuff and process problems.

The first factor influencing the efficiency level of patient flow planning in a worse way iscomplexity. Examples of complexity are according to Harper ${ }^{(8)}$ : rules governing patient admissions into the hospital, patient-flows through the hospital and constraints imposed by other hospital services.

With rules, he gives the example of "always keeping some beds available for emergency patients." Harper ${ }^{(8)}$ explains complexity concerning patient-flows through the hospital as "referring a patient to a different department, when there isno available bed at the department where the patient needs to receive its treatment."

Moreover, limited resources as Harper ${ }^{(8)}$ stated: "there are not enough doctor's at work, while the operating room is free, the patient is waiting to receive treatment and there isan inpatient bed available for the patient to recover after the surgery." In conclusion, the higher the amount of limited resources, and more resources, such as for example sterile equipment or inpatient beds are not available, the longer the patient has to wait to receive treatment, the lower the efficiency of patient flow planning will become.

Cardoen, et al. ${ }^{(3)}$ stated that, there are four different kinds of uncertainty that have worsened the efficiency of patient flow planning, namely: arrival uncertainty, duration uncertainty, uncertainty in the 
estimated contribution margin of surgeons and resource uncertainty. With duration uncertainty, the length ofstay in the hospital can be an example of which. Not knowing when the patient is able to leave the hospital, will again give uncertainty about when the resources, for example an inpatient bed, occupied by this patient will be free again to be used for another patient.

The process problems like, lacking of process standardization, unclear where the process starts and no one person responsible are the most important factors lead to long time loss. However, nearly all surveyed $(89 \%)$ report some patient flow issues, with "poor communication" listed most frequently as the cause of system problem. Others inthe list are,ineffective scheduling of activities and resources, lack of beds, lack of staff to help facilitate patient flow, poor centralized knowledge about the location and status of each patient. Communications is considered the most widespread and challenging root cause of patient flow obstacles, and hospitals are taking multiple actions for improvement. These include changes to staffing (hospitalists), processes (bed meetings, improved discharge coordination, etc.) and information systems (EHRs; integration with physician offices; and patient, staff and equipment tracking systems) ${ }^{(9)}$.

As stated in a recent study by the American College of Emergency Physicians (10) "A multitude of factors are responsible for crowding, including higher patient acuity, prolonged Emergency department evaluations, inadequate inpatient bed capacity, a severe nursing shortage, problems with access to on-call specialists and the use of the Emergency department by those with no other alternative to medical care, such as the uninsured".

Reducing the time from admission to senior medical assessment may be facilitated not just through changing consultant rotes but also by changing working patterns for junior doctors. The first delay encountered by most emergency patients is in waiting for an initial assessment by a junior doctor. However, in analysing demand, the improvement team found that there was, in fact, sufficient overall junior doctor capacity to review all presenting emergency patients within an hour of their arrival at hospital ${ }^{(1)}$.

Improving the quality of a system also reduces costs. If quality is improved by removing wasteful tasks from a process, the cost of staff time performing the tasks and caring for patients while they wait for them to be performed is reduced. If service capacity is planned to meet the average demand, patients will have to wait (queue) when demand is higher than average. However, when the demand is lower than average, the unfilled capacity cannot be carried forward to the future and is effectively lost ${ }^{(11)}$.

Those worse effects could be overcome by Lean methodology - the basis of the world famous Toyota production model - aims to provide what the customer wants, quickly, efficiently and with as little 'waste' as possible. Its application to healthcare lies in streamlining and improving the quality of processes by minimising or eliminating waste (including Confusion, Movement, Extra Processing, Waiting, Defects and Overproduction) maximising what adds value to patients.

1- Confusion: People doing the work are not confident about the best way to perform tasks, 2Movement: Is there unnecessary (non-value-added) movement of parts, materials, or information between processes, 3- Waiting: Idle time created when people, information, equipment, or materials are not at hand, 4Extra Processing: Activities that do not add value from the patient's perspective, 5- Defects: Work that contains errors or lacks something of value. Does the process result in anything the customer would deem unacceptable, 6- Overproduction: Redundant work, are we producing faster than the customer needs? ${ }^{(12)}$.

All the previous mentioned factors have a (negative, bad or worsen) effect on the efficiency level of patient flow planning, but of course, there are also factors that have a (positive, good or improving ) influence on the efficiency level of planning. In the coming sections, three of them will be explained, namely: the number of elective patients, the IT-systems, the level of cooperation between departments and physical design of departments.

Thereare different kinds of patients that a hospital needs to provide with treatment. For this subsection, only elective and non-elective patients are taken into account, because these are the main categories. According to Adan, et al. ${ }^{(13)}$, elective patients are patients for whom a surgery can be well plannedin advanced, for non-elective this is not the case. For non-elective patients however, planning is more difficult, because it was not known in advance that they were coming to the hospital.

Therefore, the higher the number of elective patients, compared to the number of non-elective patients, the lower the uncertainty of not knowing how many patients will come and what kind of treatments they will need, the easier it becomes to make a planning and thus a more efficient planning. Hence, this shows the positive influence of this factor on the efficiency of patient flow planning.

The next factor to be discussed is the advancement of information technology (IT) systems. "IT systems are systems that store and provide information about patients, such as the number of patients and the results from an x-ray scan," as has been said by Menon, et al. ${ }^{(14)}$ They also state, "The use of IT capital has positive influence on the production of output and thus the efficiency of the planning." The more advanced the IT facilities of a hospital are, the better available the information about the patients and kinds of patients become for the entire hospital, and therefore the better the overview of knowing which patients are where and what treatment have they received and need to receive. All this information and overview, makes it easier to plan 
what, where, who and when. In the end, this enables a more efficient planning. The advancement of IT systems and alongside the better valuable the information about patients therefore has a positive influence on the efficiency of patient flow planning.

Other factor that has an improving influence on the efficiency of patient flow planning is the level of cooperation between departments. They claim, "The interest of hospital departments is currently not in line with the interests of the entirehospital". This means that not all departments work in the best interest of the whole hospital, but more in the best interest of their own department. The efficiency of hospitals is a hot issue, as stated by Ludwig et al. ${ }^{(15)}$.

Beaudry et al. ${ }^{(2)}$, therefore cooperation should be of high importance to the sub departments of a hospital. When departments share more information with each other, and thus cooperate more, amore efficient planning can be made, because of this cooperation more information can be shared and can improve both individual department planning efficiency and total planning efficiency.

Physical design is also important in assisting internal way finding by ensuring that interdependent services/departments are co-located, and by reducing movement around the site ${ }^{(16)}$.

In the case of outpatient departments, it is important that the reception is directly visible from the main entrance. This will help to ensure that people go directly to the reception staff on arrival. According to the NHS Institute for Innovation and Improvement ${ }^{\left({ }^{17}\right)}$ for improving way finding patients require direct (but controlled) visual and physical access from the waiting areas to treatment rooms, and staff members require direct routes between the treatment rooms and the staff location as they visit different patients.

According to Becker ${ }^{(18)}$, the physical design that increases the visibility and accessibility of the receptionist is likely to facilitate more opportunities for positive interaction.

Surveillance of the waiting areas is necessary for a number of aspects of care delivery, including: controlling access into the department; identifying incidents of inappropriate or criminal behavior; monitoring patients and identifying if their condition becomes a cause for concern ${ }^{(17)}$. Therefore, visibility and accessibility have a significant impact on the patients' perception of journey and satisfaction.

\section{Conclusion and recommendation}

By knowing the factors that have a (negative, bad or worsen) influence on the efficiency of patient flow planning and the factors that have a (positive, good or improving ) influence, the efficiency of the hospital could be increased through overcoming the negative factors and improving the positive one in the planning process.

\section{References}

[1]. Blackley J, Burley G, Duffy $M$ et al. Improving patient flow. The Health Foundation. 2013. Retrieve from www.health.org.uk/enewsletter

[2]. Beaudry A, Laporte G, Melo T, Nickel S. Dynamic transportation of patients in hospitals.OR Spectrum. 2010; $32: 77-107$.

[3]. Cardoen B, Demeulemeester E, Beliën J. Operating room planning and scheduling; a literature review. European journal of Operational Research, 2009; 201: 921-932.

[4]. Vos L, Groothuis SG, Van Merode G. Evaluating hospital design from an operations management perspective. Health Care Management Sciences. 2007; 10:357-364.

[5]. Belson David. Improving Efficiency in the Safety Net: Management Engineering Practice and Cases. California HealthCare Foundation. 2010.

[6]. Cayirli T, Veral E. Outpatient scheduling in health care: a review of literature. Production and Operations Management. 2003; 12:519-549.

[7]. Haraden C PH D, Resar R MD. Patient flow in hospitals; understanding and controlling it better. Frontiers of Health Services Management.2004.

[8]. Harper, PR. A Framework for Operational Modelling of Hospital Resources. Health Care Management Science. 2002 ; 5:165-173.

[9]. Badri M A, Hillingsworth J. A simulation model for scheduling in the emergency room. International Journal of Operations and Production Management. 1993; 13:13-24.

[10]. American College of Emergency Physicians, ACEP Responding to emergency department crowding: a guidebook for chapters; 2002.

[11]. Baker M, Taylor I, Mitchell A. Making Hospitals Work: How to improve patient care while saving everyone's time and hospitals' resources. Goodrich, UK: Lean Enterprise Academy;2009

[12]. Ezzat A E M. Improving planning efficiency in operation theatre by using Lean Thinking. Middle East journal of Applied Sciences. 2014; 4: 513-519.

[13]. Adan, I, Bekkers J, Dellaert N, Vissers J, Yu X. Patient mix optimisation and stochastic resource requirement: A case study in cardiothoracic surgery planning. Health care management sciences. 2009; 12: 129-141.

[14]. Menon N M, Lee B, Eldenburg L. Productivity of Information Systems in the Healthcare Industry. Information Systems Research. 2000;11:83-92

[15]. Ludwig M, Van Merode F, Groot W. Principal agent relationships and the efficiency of hospitals. 2008. Retrieved from:http://www.springerlink.com/content/t0w5510266448q48/fulltext.pdf.

[16]. NHS Greater Glasgow's Community \& NHSGG. Report on initial scoping exercise to determine patient and cares views on the physical design of the New South Glasgow Hospital. 2006. Retrieved from http://library.nhsggc.org.uk/mediaAssets/Community\%20Engagment/NewSGHFinal.pdf.

[17]. NHS Institute for Innovation and Improvement. Patient flow: Quality and service improvement tool. 2008. Retrieve from http://www.institute.nhs.uk/quality and service improvement tools/quality and service improvement tools/patient flow.html.

[18]. Becker F. Ambulatory facility design and patient's perception of healthcare quality. Health Environments Research \& Design. 2008; 1:35-54. 